\title{
Gold-Activated Zinc Sulphide Phosphors
}

\author{
DEVELOPMENT, PROPERTIES AND APPLICATIONS
}

\author{
Masaaki Tamatani \\ Toshiba Corporation, Kawasaki, Japan
}

\begin{abstract}
Over the past few years, phosphors of the gold-activated zinc sulphide type have been developed for use in television tubes. They are now applied for this purpose on a large scale by manufacturers in Japan and, as a result, their luminescence is a familiar feature in homes throughout the world. The scientific and technical background to the development of these products is presented here and their applications are described.
\end{abstract}

Materials which are luminescent are known as phosphors. They have the property of emitting light at temperatures substantially below those which produce incandescence when they are excited by exposure to electron beams or to radiation, especially in the $x$-ray and ultra-violet parts of the spectrum. The emitted light may be confined to certain wavelengths and may therefore be coloured. In a cathode-ray tube or television tube, the face-plate or screen is coated with one or more phosphors and becomes luminescent over areas which are impacted by beams of electrons from the cathode. These beams can be used to display signals or create pictures in different colours on the screen.

To be suitable for use in cathode-ray and television tubes, phosphors must have certain special properties. Thus:

(1) They should emit light of the desired colour(s). That is, they should have appropriate luminescence spectra

(2) The efficiency with which they convert the energy of electrons incident upon them into visible light (luminous efficiency or luminescence power efficiency) must be high

(3) They must be chemically stable not only during tube fabrication, but also under electron bombardment

(4) Their luminescence should persist for an adequate period after excitation by an electron beam has ceased (for instance, up to 10 per cent of the luminescence must be retained after 0.02 to 1 millisecond in a television tube and after 1 second on a radar screen).

Although many thousands of luminescent materials are known, only about 50 phosphors are now used in commercially fabricated tubes (1). They are all inorganic, non-metallic, crystalline substances with particle sizes in the range 1 to $20 \mu \mathrm{m}$.

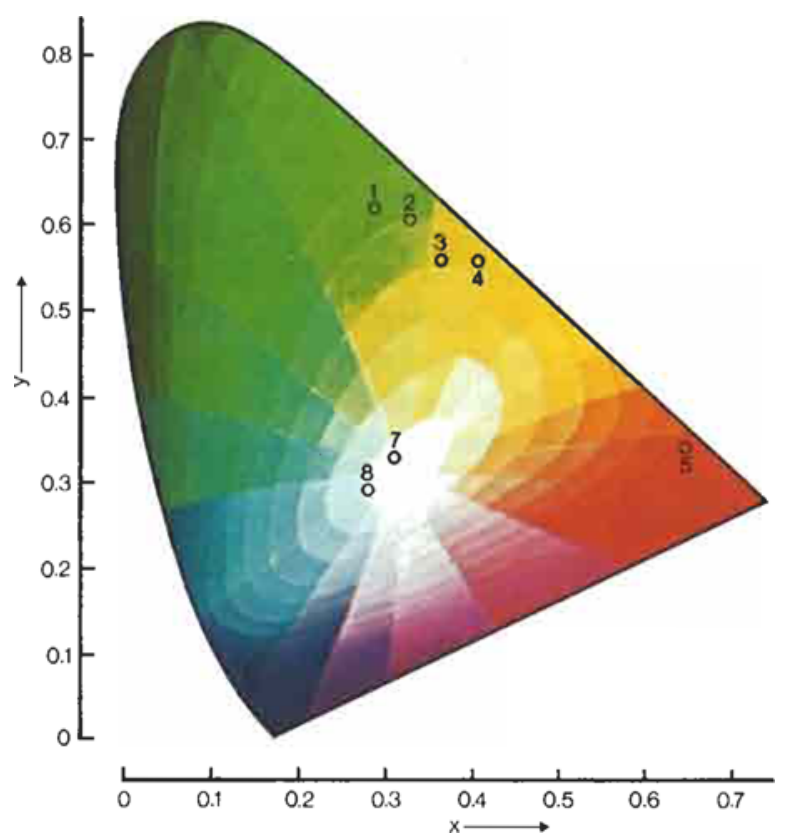

Fig. 11931 CIE co-ordinates $x$ and $y$ (chromaticity) of the light enitted by various phosphors used in television picture tubes. Also plotted in this illustration are the two stindard white shades for black-and-white and colour tubes respectively.
$1 \mathrm{ZnS:Cu}$
2 (Zn,Cd)S:Cu (colour tubes)
$3 \mathrm{ZnS:Au}$
4 (Zn,Cd)S:Cu (black-and-white tubes)
$5 \mathrm{Y}_{2} \mathrm{O}_{2} \mathrm{~S}: \mathrm{Eu}$
6 ZnS: Ag
$7 \mathrm{D}_{6500}$ white (colour tubes)
$810000 \mathrm{~K}$ white (black-and-white tubes)

The chromaticity of the light enitted by a phosphor consisting of a physical mixture of two luminescent components is a point on the straight line connecting the positions corresponding to the individual components. The 1931 C.E representation was discussed in Gold Bull., 1979 , 12, (1), 9-19

This $1931 \mathrm{CIE}$ chromaticity chart is reproduced with permission of the Optical Society of America (2) 
Fig. 2 This photomicrograph of the screen of a television tube under light-ennitting conditions shows how alternating stripes of tliree phosphors with blue, green and red luminescence respectively, are arranged to produce a colour picture $\quad \times 30$

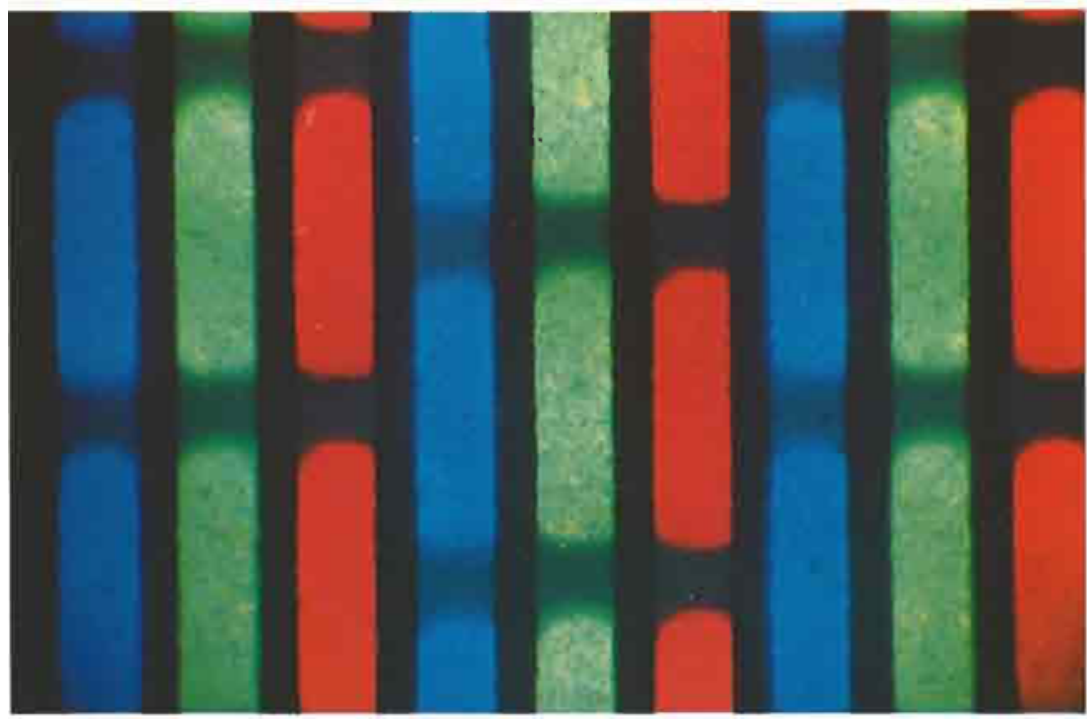

\section{Improvements in Television Phosphors}

Of the various kinds of cathode-ray tube which are manufactured, black-and-white and colour television picture tubes for home viewing have the largest market. About 50 per cent of the colour tubes used throughout the world are produced in Japan. On a world-wide basis, television tube manufacture consumes annually more than 300 tons of phosphors. Understandably, over the last 30 years, much effort has been devoted to attempts at improving these phosphors.

A black-and-white television picture tube consists of an electron gun and a white-emitting screen which is coated with a mixture of phosphors about $20 \mu \mathrm{m}$ thick. By careful proportioning and physical mixing of yellow- and blue-emitting phosphors, the resultant light is blue-white in colour. It is adjusted by most manufacturers to a colour temperature between 9000 and $15000 \mathrm{~K}$ (see Figure 1). The blue-emitting phosphor used initially, and still used today, is silveractivated zinc sulphide, $\mathrm{ZnS}$ : Ag. The yellow-emitting phosphor first used was silver-activated zinccadmium sulphide, $(\mathrm{Zn}, \mathrm{Cd}) \mathrm{S}: \mathrm{Ag}$, but it suffered deterioration during tube processing, especially during baking, and its place was taken about ten years ago by copper-activated zinc-cadmium sulphide, (Zn,Cd)S:Cu.

In a colour television picture tube, a 'set' of three different phosphors is used, of which one luminesces in the red, one in the green and one in the blue. They are applied to the screen in 'triplets' of stripes or dots, 0.1 to $0.2 \mathrm{~mm}$ in width, with each triplet containing one stripe or dot of each phosphor as illustrated in Figure 2. Three electron guns are arranged so that each primary colour can be produced on the screen at will, by selectively exciting the appropriate phosphor stripes or dots.
Since they were first developed, the efficiency of colour picture tubes as producers of white light has been increased by a factor of 6 , from 8 to 48 lumens/watt (3). About half of this increase was achieved before 1970 as a result of continuous and intensive effort devoted to phosphor improvement. Since 1970, however, increases in efficiency have been obtained mainly through innovations in tube design.

The blue primary $\mathrm{ZnS}: \mathrm{Ag}$ phosphor used initially remains basically unchanged. Development of europium-activated red primary phosphors contributed to a large increase in tube efficiency in the late 1960's, and an yttrium oxysulphide $\left(\mathrm{Y}_{2} \mathrm{O}_{2} \mathrm{~S}\right.$ : Eu) has been the most commonly used red primary phosphor emitter throughout the world since 1967. For green primaries, low-efficiency manganese-activated phosphors were replaced by $(\mathrm{Zn}, \mathrm{Cd}) \mathrm{S}: \mathrm{Ag}$ in 1961 and by $(\mathrm{Zn}, \mathrm{Cd}) \mathrm{S}: \mathrm{Cu}$ in 1968.

The requirements for satisfactory colour picture tubes are more exacting than those for black-andwhite tubes. This is particularly the case in regard to current ratios (the ratios of the three electron beam currents necessary to obtain the specified white shade on the screen). Since the size of the spot generated by an electron beam increases with beam current, equal beam currents for the three guns in the tube are desirable to minimize colour fringing on peak whites. The current ratios are determined by the phosphor set used and the specified white shade (4). In most countries, $D_{6500}$ white, which is shown in Figure 1 as a point of chromaticity co-ordinates $\mathrm{x}=0.313$ and $y=0.329$, is the standard white shade used in colour television receivers. The current ratios were well balanced with a phosphor set of blue-emitting $\mathrm{ZnS}: \mathrm{Ag}$, green-emitting $(\mathrm{Zn}, \mathrm{Cd}) \mathrm{S}: \mathrm{Cu}$ and redemitting $\mathrm{Y}_{2} \mathrm{O}_{2} \mathrm{~S}$ : Eu (Table I). 
Table I

Beam Current Ratios Necessary to Obtain the $D_{6500}$ White Shade and Relative White Brightnesses of Colour Television Picture Tubes Incorporating Various Green-Emitting Phosphors. After (6)

\begin{tabular}{c|c|c|c}
\hline $\begin{array}{c}\text { Green- } \\
\text { emitting }\end{array}$ & \multicolumn{2}{|c|}{ Beam current ratios } & White \\
phosphor & red/blue & red/green & brightness* * \\
\hline (Zn,Cd)S:Cu & 1.7 & 1.0 & 108 \\
ZnS:Cu & 2.2 & 1.3 & 100 \\
ZnS:Au,Cu & 1.7 & 1.1 & 107
\end{tabular}

-The blue- and red-emitting phosphors are $\mathrm{ZnS}: \mathrm{Ag}$ and $\mathrm{Y}_{2} \mathrm{O}_{2}$ S: Eu respectively.

"Arbitrarily taken as 100 for tubes incorporating $\mathrm{ZnS}: \mathrm{Cu}$ as green, emitter.

In the early 1970's, however, environmental pollution became of great concern in Japan. In particular, attention was focussed on the risk to health created by cadmium compounds which were discharged in river and sea water from certain chemical factories and mines. Japanese phosphor manufacturers therefore ceased producing cadmium compounds in order to minimize the health hazards to their workers and the people living near the factories. In the history of phosphors, similar situations had occurred at least twice before. Thus, the use of excellent yellow- and red-emitting phosphors, zinc-beryllium silicate and magnesium arsenate respectively, had been abandoned because of the toxicity of beryllium and arsenic compounds.

A $\mathrm{ZnS}: \mathrm{Cu}$ phosphor, which has a cubic crystal structure, was introduced as an alternative for the yellowish green-emitting hexagonal $(\mathrm{Zn}, \mathrm{Cd}) \mathrm{S}: \mathrm{Cu}$ phosphor in 1971. This had a luminous efficiency comparable with that of its cadmium-containing counterpart, but had serious disadvantages resulting from its greener luminescent colour. Thus, tube white brightness (the luminance of the white shade produced at a fixed total blue + green + red beam current) was reduced by about 10 per cent and current ratios for the $D_{6500}$ white became unbalanced $(5,6)$ (Table I). For these reasons, a search was begun for other phosphors with a yellowish green luminescent colour and which could be used without detriment to tube white brightness.

\section{Gold-Activated Zinc Sulphide Phosphors}

Colorimetric calculations indicate that the same tube white brightness can be obtained using a phosphor of lesser luminous efficiency than $\mathrm{ZnS}: \mathrm{Cu}$, but with a more yellowish luminescence. Figure 3 shows on the 1931 CIE chromaticity chart some phosphors which could be regarded as candidates for a green primary of this type (5). In practice, the low efficiencies of terbium-activated indium borate, $\mathrm{InBO}_{3}: \mathrm{Tb}$, and lanthanum oxysulphide, $\mathrm{La}_{2} \mathrm{O}_{2} \mathrm{~S}: \mathrm{Tb}$, militate against their use. Cerium-activated calcium sulphide, $\mathrm{CaS}: \mathrm{Ce}$, is chemically unstable in the polyvinyl alcohol-ammonium dichromate binder which is used for the application of the phosphor to the face-plate of a tube by a screen printing process. Terbium-activated lanthanum oxybromide, LaOBr:Tb, has the disadvantage of high cost and is difficult to apply to television screens. Gold-activated zinc sulphide $\mathrm{ZnS}: \mathrm{Au}$, however, has sufficient luminous efficiency for producing tubes with the same white brightness as those incorporating $\mathrm{ZnS}: \mathrm{Cu}$. This phosphor is nevertheless not suitable for use as a green primary because its luminescence is too yellow, a feature which would excessively restrict the range of colours displayed by a television tube. However, it has been found that this disadvantage of
Fig. 3 Colorimetrically calculated relationship between the cliromaticity of yellowish green-emitting phosphors and white brightness in a colour television picture tube. The straight lines indicate the chromaticities and relative luminous efficiencies required for green-emitting phosphors to give the same white brightness as $\mathrm{ZnS}$ : $\mathrm{Cu}$, when used in combination with the fixed red $\left(\mathrm{Y}_{2} \mathrm{O}_{2} \mathrm{~S}:\right.$ Eu) and bhe (ZnS:Ag) primaries. The luminous efficiencies of the phosphors relative to $\mathrm{ZnS}$; $\mathrm{Cu}$ are also shown in parentheses. After (5)

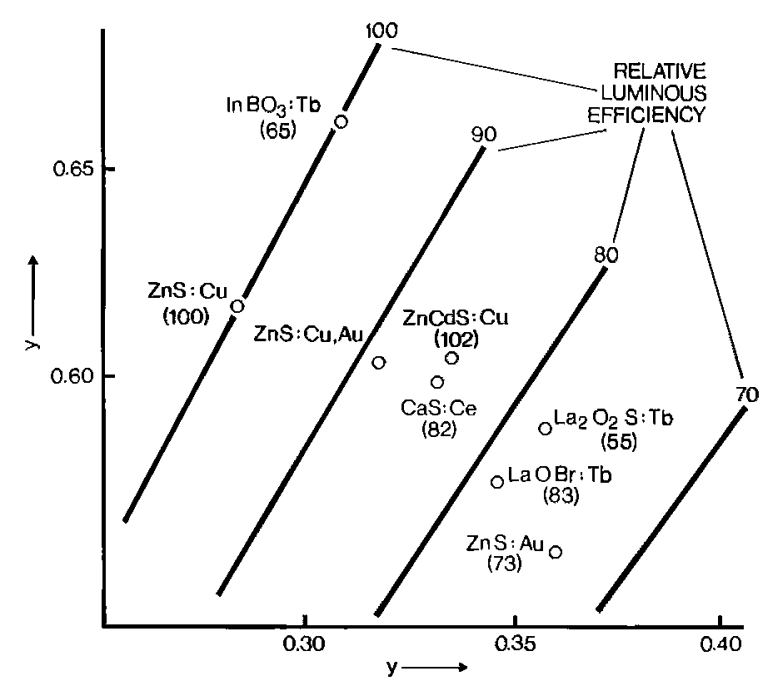


$\mathrm{ZnS}: \mathrm{Au}$ can be overcome by using it in admixture with $\mathrm{ZnS}: \mathrm{Cu}(7,8)$. The $\mathrm{ZnS}: \mathrm{Au}-\mathrm{ZnS}: \mathrm{Cu}$ physical mix has a chromaticity and a luminous efficiency which make it acceptable as a primary colour phosphor for tubes of good white brightness. An even more favourable choice is a $\mathrm{ZnS}$ phosphor simultaneously activated with copper and gold ( 9 , 10). This phosphor, $\mathrm{ZnS}: \mathrm{Au}, \mathrm{Cu}$, has a higher luminous efficiency and purer (more saturated) luminescent hue than the $\mathrm{ZnS}: \mathrm{Au}-\mathrm{ZnS}: \mathrm{Cu}$ mixture. The white brightnesses and current ratios of colour television tubes incorporating various yellow- to green-emitting phosphors are compared in Table I.

Since 1977, the newly developed $\mathrm{ZnS}: \mathrm{Au}, \mathrm{Cu}$ phosphor has been used in colour picture television tubes made to the $\mathrm{D}_{6500}$ white specification by Toshiba Corporation, and it is now present in about half of the colour tubes produced in Japan.

For black-and-white tubes, a physical mixture of $\mathrm{ZnS}: \mathrm{Ag}, \mathrm{ZnS}: \mathrm{Cu}$ and $\mathrm{Y}_{2} \mathrm{O}_{2} \mathrm{~S}: \mathrm{Eu}$, used as the three primaries in cadmium-free colour tubes, was considered a promising alternative to the toxic mixture $\mathrm{ZnS}: \mathrm{Ag}-(\mathrm{Zn}, \mathrm{Cd}) \mathrm{S}: \mathrm{Cu}$. The new material, however, contained a considerable amount of a red-emitting $\mathrm{Y}_{2} \mathrm{O}_{2} \mathrm{~S}$ :Eu phosphor, whose light output varies linearly as a function of electron beam current, whereas light output from zinc sulphide phosphors tends towards saturation at high beam current. This led to a luminescence of a marked reddish white colour at high currents. The use of a $\mathrm{ZnS}$ :Au phosphor, instead of the $\mathrm{ZnS}: \mathrm{Cu}$ green primary, solved the problem. Since the gold-activated phosphor has a yellow luminescence, admixture with only a small amount of a red-emitting phosphor is sufficient to produce an acceptable white $(11,12)$. $\mathrm{ZnS}$ :Au is produced commercially as a yellow component phosphor in Japan, though using it, tube brightness is about 10 per cent lower than with the older combination incorporating the cadmium-containing phosphor.

\section{Luminescence Spectra}

Figure 4 illustrates the mechanism of luminescence in $\mathrm{ZnS}$ (13). When monovalent gold (or silver or copper) is substituted as an 'activator' at divalent zinc sites in the host crystal, an impurity energy level is formed above the valence band. Trivalent aluminium, when used as a 'co-activator', also replaces divalent zinc ions and compensates for the imbalance in electric charges in the host crystal induced by the incorporation of gold. Aluminium forms a shallow impurity level below the conduction band of the host crystal. Under cathode-ray excitation, electrons in the valence band are raised into the conduction band and trapped at aluminium sites. Simultaneously, holes produced in the valence band are trapped at gold sites. Luminescence takes place as a result of recom-

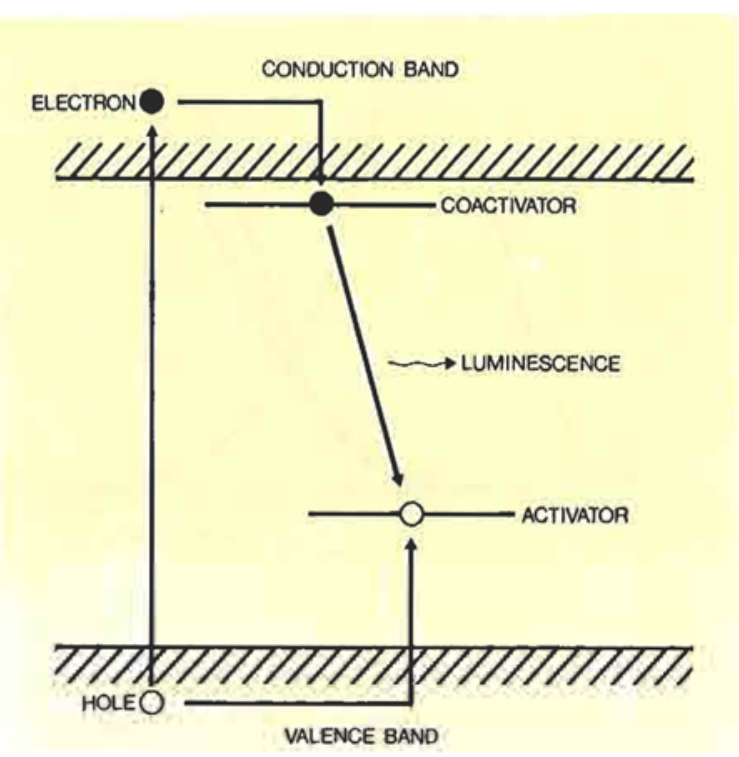

Fig. 4 Schematic representation of co-activated luminescence in $\mathrm{ZnS}$. This type of luminescence has the highest efficiency under cathode-ray excitation among various kinds of broad-band luminescence observed in ZuS (14)

bination across the band gap of the trapped electrons and holes. The energy liberated by this recombination determines the wavelength of the luminescence. Thus, with aluminium as a co-activator and gold, silver or copper as activators, yellow, blue or green colours respectively are produced (Figure 5).

By varying the cadmium/zinc ratio, the band gap energy of $(\mathrm{Zn}, \mathrm{Cd}) \mathrm{S}$ phosphors can be adjusted continuously between $3.90 \mathrm{eV}$, its value for pure $\mathrm{ZnS}$, and $2.58 \mathrm{eV}$, its value for pure $\mathrm{CdS}$. The position of activator levels with respect to the valence band is little affected by variations in the composition of the host crystal. Therefore, luminescent colours varying from blue to deep red can be obtained by adjusting the cadmium/zinc ratio of $(\mathrm{Zn}, \mathrm{Cd}) \mathrm{S}$ activated with one or more of silver, copper and gold. Similarly, a shift towards more yellowish colour, observed in the luminescence in $\mathrm{Zn}(\mathrm{S}, \mathrm{Se}): \mathrm{Au}$ is attributed to a decrease in the band gap energy when selenium is substituted in part for sulphur $(15,16)$.

$\mathrm{ZnS}$ has two crystal structures; a hexagonal structure which is formed on heating above $1020^{\circ} \mathrm{C}$ and a cubic structure stable below $1020^{\circ} \mathrm{C}$. Band gap energies for hexagonal and cubic $\mathrm{ZnS}$ are 3.90 and $3.83 \mathrm{eV}$ respectively. Depending on its structure, therefore, with the same activator $\mathrm{ZnS}$ can form phosphors emitting light of different colours. For instance, gold promotes a yellow luminescence in cubic $\mathrm{ZnS}$ and a green one in hexagonal $\mathrm{ZnS}$.

It may be noted that the incorporation of a small amount of bismuth or antimony into the structure of 


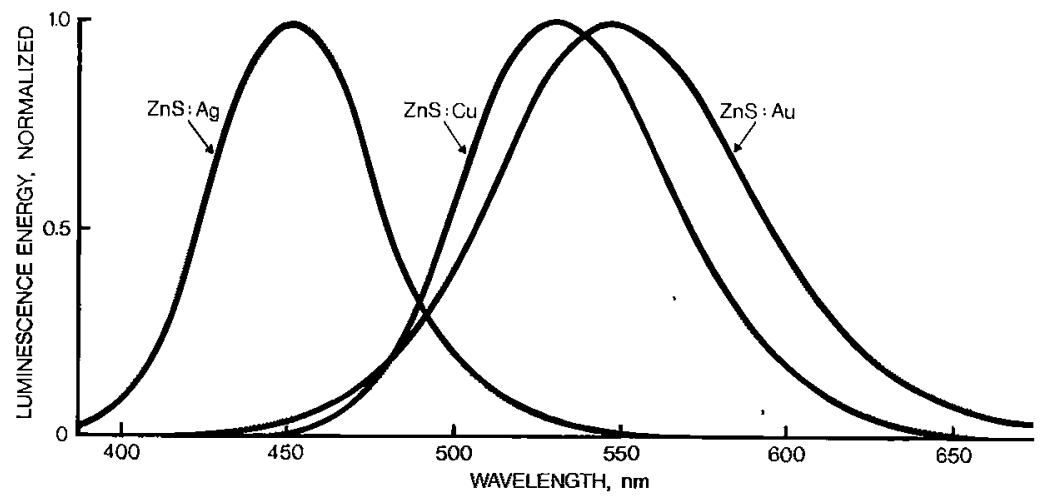

Fig. 5 Spectral energy distribution of the luminescences of cubic ZnS:Ag, ZnS:Cu and ZinS:Au

the host crystal has been proposed as a means of making the luminescent colour of $\mathrm{ZnS}: \mathrm{Au}$ slightly more yellow $(17,18)$.

\section{Preparation}

An activator concentration of less than 0.05 weight per cent $(500 \mathrm{ppm})$ is adequate in $\mathrm{ZnS}$ phosphors. A consequence is that metallic element impurities in the ppm range can also affect the luminous efficiency and/or the colour adversely. Great care is therefore necessary to remove impurity metals, in particular iron, before $\mathrm{ZnS}$ is precipitated from a zinc sulphate solution by hydrogen sulphide gas. Such removal is usually effected by oxidation and precipitation of the iron as iron(III) hydroxide.

After the $\mathrm{ZnS}$ precipitate has been separated, aqueous solutions of chloroauric acid and aluminium nitrate are added to it, together with 'flux' materials, and the resulting slurry is well mixed and dried. A powder with a particle size of about $1 \mu \mathrm{m}$ is obtained which is fired in a quartz or alumina crucible at a temperature of 900 to $1000^{\circ} \mathrm{C}$. During the firing process, crystallites from 5 to $10 \mu \mathrm{m}$ in size develop, the activators are incorporated into the $\mathrm{ZnS}$ lattice and the luminescent phosphor results (Figure 6).

Firing is carried out under a reducing atmosphere, because oxygen, even in very small amounts, prevents the diffusion of aluminium ions into the $\mathrm{ZnS}$ lattice. Hydrogen sulphide, carbon disulphide or a hydrogennitrogen mixture are used as firing atmospheres. The presence of sulphur and active carbon powder in the crucible is also useful in some cases for maintaining reducing conditions.

The 'flux', 0.1 to 5 weight per cent in the $\mathrm{ZnS}$ powder, is usually a mixture of alkali- and alkaline earth-metal halides, such as sodium chloride and magnesium chloride. Not only does it promote crystallization during the firing, but it also contributes to the formation of luminescence centres by introducing halogen ions into the $\mathrm{ZnS}$ lattice. For a gold-activated phosphor, a blue luminescence band, which is not desired for practical use, tends to appear if chloride fluxes are present. This blue band can be avoided by preparation methods differing from those for copper- and silver-activated phosphors. These may involve addition of fluorides (19) or rubidium and cesium compounds (20), or careful control of the atmosphere (21) and cooling rate after firing (22).

\section{Properties}

In the earlier days of television, silver- and copperactivated $\mathrm{ZnS}$ phosphors, which have high luminous efficiencies, were widely investigated and used. The gold-activated phosphors then available had relatively low efficiency blue-green luminescence and it was generally assumed that the gold luminescence centres differed considerably in character from those formed by copper and silver. Some investigators considered that gold acted as a 'poison' rather than an activator of phosphors (23).

In 1950, however, Kröger and Dikhoff (24) introduced trivalent metals as co-activators in place of the halides which earlier workers had used. They showed that the gold luminescence spectrum was composed of two bands, at wavelengths of 470 and $530 \mathrm{~nm}$, and that the latter became predominant in the presence of a trivalent metal co-activator. The two gold bands were assumed to correspond to the blue and green bands of copper. This similarity between gold and copper as activators was later confirmed by Henderson et al. (22) in chloride co-activated ( $\mathrm{Zn}, \mathrm{Cd}) \mathrm{S}$. Van Gool (25) reviewed the similarity and presented a diagram which summarizes the relationship between the characteristics of luminescence in $\mathrm{ZnS}$ and the concentrations of activators and $\mathrm{CO}^{-}$ activators in it.

Although similarities between activation by gold and copper exist, some peculiarities have been observed in $\mathrm{ZnS}: \mathrm{Au}$. Its luminous efficiency is about 70 to 80 per cent of that of $\mathrm{ZnS}: \mathrm{Cu}$, halides are not effective as co-activators of gold (21) and a co-activated luminescence appears even when no co-activator is 
Table II

Luminescence Characteristics of Green-Emitting Phosphors under Cathode-Ray Excitation $\left(10 \mathrm{kV}, 1 \mu \mathrm{A} / \mathrm{cm}^{2}\right)$. After (31)

\begin{tabular}{|c|c|c|c|c|}
\hline $\begin{array}{l}\text { Green- } \\
\text { emitting } \\
\text { phosphor }\end{array}$ & $x$ & $y$ & $\begin{array}{l}\text { Relative } \\
\text { luminous } \\
\text { efficiency }\end{array}$ & $\begin{array}{c}\text { Relative } \\
\text { power } \\
\text { efficiency }\end{array}$ \\
\hline $\begin{array}{l}\mathrm{ZnS}: \mathrm{Au}, \mathrm{Cu} \\
(\mathrm{ZI}, \mathrm{Cd}) \mathrm{S}: \mathrm{Cu} \\
\mathrm{ZnS}: \mathrm{Cu} \\
\mathrm{ZnS}: \mathrm{Au}\end{array}$ & $\begin{array}{l}0.315 \\
0.330 \\
0.285 \\
0.363\end{array}$ & $\begin{array}{l}0.604 \\
0.607 \\
0.618 \\
0.560\end{array}$ & $\begin{array}{r}91 \\
100 \\
96 \\
69\end{array}$ & $\begin{array}{r}94 \\
100 \\
101 \\
73\end{array}$ \\
\hline
\end{tabular}

-Arbitrarily taken as 100 for (Zn,Cd)S:Cu.

${ }^{+}$Power efficiency: the ratio of the radiant energy from the phosphor to the electrical energy from the electron beam dissipated in it.

introduced (21). Also, the body colour of the phosphor is not rapidly changed to grey by unbalancing the gold/aluminium concentration ratio $(21,26)$ and luminescence bands other than the co-activated band behave differently from those due to copper and silver $(21,27)$. A model recently proposed for the blue luminescence centre in $\mathrm{ZnS}: \mathrm{Au}$ does not resemble models for this centre in $\mathrm{ZnS}: \mathrm{Cu}$ and $\mathrm{ZnS}: \mathrm{Ag}$ (28).

These inconsistencies still remain unexplained. However, they may arise from the large ionic radius of gold and from the incorporation of this metal in the $\mathrm{ZnS}$ host structure in the trivalent as well as the monovalent state (26).

\section{Activation by More than Two Activators}

Kröger et al. (29) reported that activated luminescence bands due to more than one activator being present in a phosphor, appear independently from each other when aluminium is used as a co-activator. These early investigators developed $(\mathrm{Zn}, \mathrm{Cd}) \mathrm{S}: \mathrm{Au}, \mathrm{Ag}$, which shows a white luminescence by superimposition of two bands (blue-silver and yellow-gold respectively), and tried to use it in black-andwhite television picture tubes. A $\mathrm{ZnS}: \mathrm{Au}, \mathrm{Ag}$ cadmium-free phosphor mixed with a small amount of a $\mathrm{Y}_{2} \mathrm{O}_{2} \mathrm{~S}: \mathrm{Eu}$ red-emitting phosphor was also proposed for the same application (30).

Fig. 6 Scanning electron micrograph of $\mathrm{ZnS}: \mathrm{Au}, \mathrm{Cu}$ phosphor particles for use in television picture tubes
Matsuura and Tamatani (31) investigated the luminescence of $\mathrm{ZnS}: \mathrm{Au}$, $\mathrm{Cu}$ which was developed as a single component green primary for colour television picture tubes. It was concluded that copperaluminium pairs are formed in preference to goldaluminium pairs in $\mathrm{ZnS}$, and that gold ions are more easily introduced into the host lattice in the presence of copper. As a consequence, the simultaneously activated phosphor $\mathrm{ZnS}: \mathrm{Au}, \mathrm{Cu}$ shows a more saturated green luminescence and higher luminous efficiency than a physical mixture of $\mathrm{ZnS}: \mathrm{Cu}$ with $\mathrm{ZnS}: \mathrm{Au}$. A single component phosphor is also easier to use than a mixture in making a screen of uniform properties. Table II compares the luminescence characteristics of $\mathrm{ZnS}: \mathrm{Au}, \mathrm{Cu}$ under cathode-ray excitation with those of products used in colour television tubes of earlier technology.

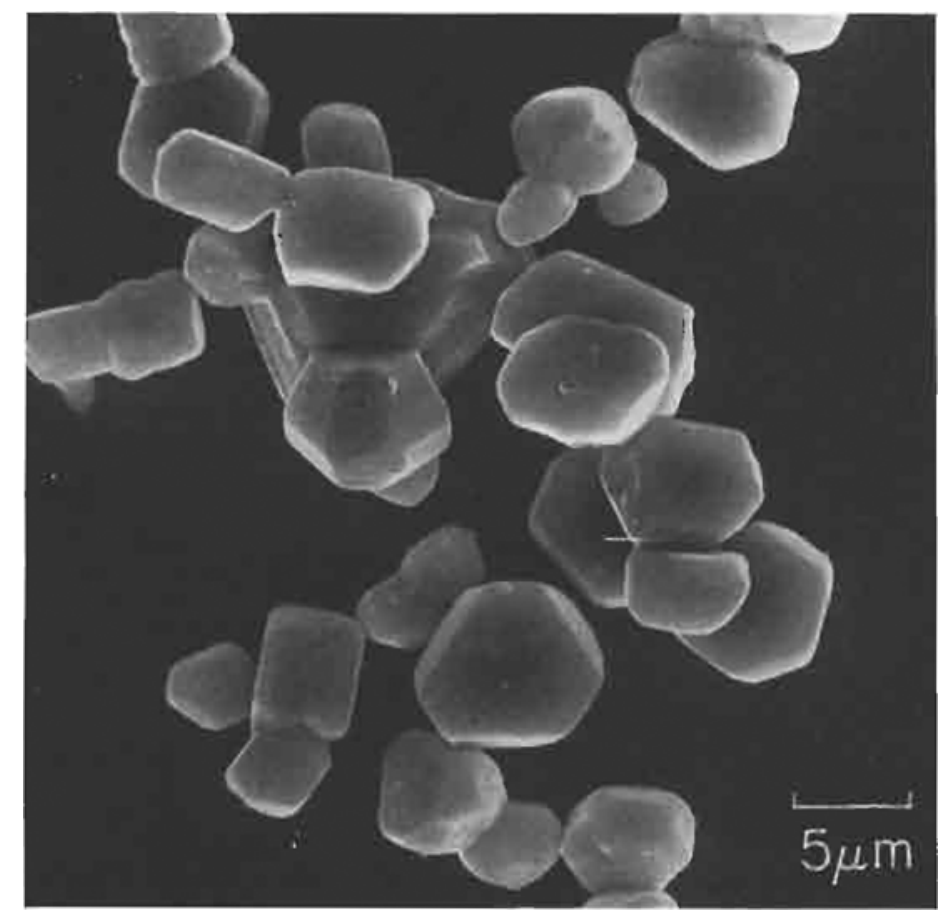




\section{Special Applications}

A white-emitting $(\mathrm{Zn}, \mathrm{Cd}) \mathrm{S}: \mathrm{Au}, \mathrm{Ag}$ phosphor was found unsuitable for commercial use in black-andwhite television tubes due to its rather low luminous efficiency. It has, however, proved effective in a special viewfinder tube, in which the screen is required to give a high degree of resolution $(32,33)$. The picture on the face plate of the tube is viewed through a magnifying lens in order to monitor a television camera. A conventional black-and-white television screen is not suitable for this application because the presence on it of both blue- and yellowemitting particles reduces its resolution.

A $\mathrm{ZnS}$ :Au phosphor is used also in a fluorescent indicator tube, in which the phosphor is excited by electrons accelerated by a low voltage of 30 to $60 \mathrm{~V}$, in contrast to the 10 to $30 \mathrm{kV}$ in television picture tubes (34). This tube displays alpha-numerical characters and is used in calculators and measuring instruments. Green-white-emitting zinc oxide was otherwise the only phosphor suitable for this purpose. Recently, tubes have been developed for use in multi-coloured displays on mass-produced audio appliances and inside automobiles. Gold-activated phosphors show the best performance as yellow-emitting substances for such devices when their electric conductivity is increased by mixing with non-luminescent indium oxide or zinc oxide.

\section{References}

1 S. Larach and A. E. Hardy, Proc. IEEE, 1973, 61, 915-926

2 Committee on Colorimetry, Optical Society of America, "The Science of Colour', Thomas Y. Crowell Co., 1953

3 A. E. Hardy, in 'Extended Abstr., Electrochen. Soc., Spring Meet., 1978', Abstract No. 323

4 C. B. Neal IEEE Trans., 1973, BTR-19, 149-162
5 S. Matsuura, T. Ito, Y Koga, M. Tamatani and Y. Ohtake, Toshiba Rev., 1978, 33, 515-518

6 T. Ito, in 'Extended Abstr., Electrochem. Soc., Spring Meet. 1978', Abstract No. 333

7 Y. Koga, T. Sumita, N. Inoue and S. Matsuura, U.S. Patent $4,151,442(1979)$

8 Y. Uehara and S. Ohmatoi, U.S. Patemt 4,140,940 (1979)

9 M. Oikawa and S. Matsuura, Japanese Prelim. Publ. 78-94281

10 R.R. Dodds and K. E. Landmesser, Japanese Prelim. Publ. 79-97591

11 T. Torii, Y. Nagashima, H.Kitamura and E. Mori, U.S Patem 3,922,233 (1975)

12 Y. Koga, W. Ichise and T. Sumita, Japanese Prelim. Publ. 78-15280

13 A. Suzuki and S. Shionoya, 7. Phys. Soc. Ipn., 1971, 31, 1455-1461 \& 1462-1468

14 S. Shionoya, in 'Luminescence of Inorganic Solids', edited by P. Goldberg, Academic Press, 1966, pp. 205-286

15 N. Kotera, S. Murakami and S. Eguchi, fapanese Prelim. Publ. $78-4784$ \& $78-14179$

16 S. Eguchi, N. Kotera and S. Murakami, fapanese Prelim. Publ. $78-14182 \& 78-14183$

17 Y. Nagashima, H. Kitamura, T. Ieda and E. Mori, Japanese Prelim. Publ. 76-4085

18 T. Ieda, N. Matsuhisa and S. Ohmatoi, Japanese Prelim. Publ. $78-142991$ \& 79-19483

19 F. A. Kröger, U.S. Patent 2,623,857 (1952) F. A. Kröger and J.A.M. Dikhoff, U.S. Patent 2,623,859 (1952)

20 N. Inoue and T. Kawamata, Japanese Prelim. Publ. 78-94282

21 M. Avinor, F. Electrochem. Soc., 1960, 107, 608-611

22 S. T. Henderson, P. W. Ranby and M. B. Halstead, F. Elecirochem. Soc., 1959, 106, 27-34

$23 \mathrm{H}$. W. Leverenz, 'An Introduction to Luminescence of Solids', Dover Publications, 1968

24 F. A. Kröger and J. A. M. Dikhoff, Physica, 1950, 16, 297-316

25 W. van Gool, Philips Res. Rep., 1961, Suppl. 3, pp. 1-119

26 T. Hoshina and H. Kawai, $\mathscr{f}$. Lumin., 1976, 12/13, 453-459

27 K. Kynev and R. Dafinova, Z. Phys. Chem. (Leipzig), 1977, 258, 394-396

28 K. Kynev and V. Kuk, Z. Naturforsch., 1979, 34A, 262-264

29 F. A. Kröger, A. Bril and J. A. M. Dikhorf, Philips Res, Rep. $1952,7,241-250$

30 Y. Koga, S. Matsuura and T. Wakatsuki, Gapanese Prelim. Publ. 79-57479

31 S. Matsuura and Tamatani, in 'Extended Abstr., Electrochem. Soc., Spring Meet., 1978', Abstract No. 334

32 A. Shigeya, Nat. Tech. Rep, 1979, 25, 197-205

$33 \mathrm{H}$. Tagawa and T. Sekiguchi, Gapanese Utility Model Publ. 75-195

34 A. Kagami, Y. Mitsumura, K. Narita and K. Kanda, in 'Abstr., 175th Meet. Phosphor Soc. Jpn.', Tokyo, 1979, pp. $7-13$

\section{A Gold Mining Museum in Johannesburg}

Over the last thirty years the centre of gravity of goid mining operations in South Africa has gradually moved away from the Johannesburg area, as new mines have been established elsewhere in the Witwatersrand basin. In the process the city, which has grown in less than a century from a scattered mining community to the major commercial and industrial centre of the country, has been losing many of its links with the past. Already some 60 mines that once flourished on the Reef are now only a memory.

All this made it imperative for a positive step to be taken to preserve the unique heritage of Johannesburg from the days when gold mining in South Africa was concentrated in its immediate neighbourhood.

The idea of creating a gold mining museum had been raised at various times over the years, but the donation by Rand Mines Properties of a section of Crown Mines - $10.5 \mathrm{hec}$ tares in area and containing the No. 14 Shaft, complete with headgear, winder house and other buildings - gave critical impetus to the project. Crown Mines was an ideal choice for a museum. It had been the world's foremost gold producer for years, and it is near the centre of Johannesburg - No. 14 Shaft being a mere $5.5 \mathrm{~km}$ from the City Hall. The decision to establish the museum at Crown Mines was taken by the gold mining members of the Chamber of Mines of South Africa in December 1978. Progress since then has been rapid and what once appeared a ghost mine has been transformed into a faithfully reconstructed and refurbished mine, typical of those in the area at the turn of the century. The complex was opened on June 5th, 1980.

The concept adopted by the South African gold mining industry is that the museum should be a living monument to its pioneers and also provide a major tourist and educational attraction. While the accent is on the early days of mining, there are also displays of modern equipment to give an insight into the latest techniques.

It is the aim of the Chamber, that the museum should become a showcase for the gold mining industry and a centre of technical and academic interest. 